\title{
Human Trafficking for Sexual Exploitation
}

\author{
Roma Ranasinghe* \\ Attorney-at-Law/Freelance Consultant, Sri Lanka
}

\begin{abstract}
This paper examines the phenomenon of human trafficking in Sri Lanka, a nation uniquely situated as an origin, transit and destination country for men, women and children trafficked for forced labour, and sexual exploitation. Sex trafficking is a type of human trafficking that disproportionately affects girls and women. Every year children, women and men become trafficking victims either in their own countries or foreign countries. The practice gravely violates human rights and is considered a transnational organized crime. Almost every country of the world is affected by human trafficking, as source, countries of transit or destinations or even combination of all the three. Often less developed countries serve as sources while more developed countries serve as destinations. This paper is the reflection of my experience at International Organization for Migration (IOM) on a counter trafficking project where the first international human trafficking case filed before the High court of Colombo and where all 3 traffickers were convicted. In Part II, I will illustrate the complexity of understanding trafficking in its full social context using the testimony of the victims I encountered during my tenure at IOM. In Part III, I will discuss control methods used against the two victims of this human trafficking case for sexual exploitation. The paper ultimately concludes that broader, victim based initiatives are necessary both to assist victims and provide a firmer basis for future trafficking prosecutions.
\end{abstract}

Keywords: human trafficking, sexual exploitation, women, crime

\section{Introduction}

Human Trafficking is defined as the acquisition and sale of human beings for the purpose of sexual slavery, forced labour or commercial exploitation for the trafficker or other. In other words, trafficking is a process of enslaving people, coercing them into a situation with no way out, and exploiting them. Despite the abolishment of slavery in the 19th century, trafficking in human beings exited as a modern form of slavery and constituted one of the most degrading types of crimes in the history of humanity. Human trafficking is defined in the Palermo Protocol (2010) as:

“(...) the recruitment, transportation, transfer, harbouring or receipt of persons, by means of the threat or use of force or other forms coercion, of abduction of fraud, of deception, of the abuse of power of a position of vulnerability or of the giving or receiving of payment or benefits to achieve the consent of a person having control over another person, for the purpose of exploitation, Exploitation shall include, at a minimum, the exploitation of the prostitution of others or other forms of sexual exploitation, forced labour or services, slavery or practices similar to slavery, servitude or the removal of organs."

Human Trafficking is an international predicament and poses one of the most serious threats to human rights and human security. It transcends national boundaries and is multidimensional in nature. In recent years it was also identified as a form of modern day slavery and as one of the greatest human rights challenges of our time. Since it is complex and multifaceted in nature, it has become one of the most transnational organized crimes to combat.

According to reports, it is a business that generates an annual profit of approximately $\$ 150$ billion. UNICEF estimates that there are around 21 million trafficked people around the world. This figure includes some 5.5 million children. According to the UNODC report on "Global Report on Trafficking in Persons (UNODC, 2018) women constitute of approximately $49 \%$ of trafficked persons and men $21 \%, 23 \%$ girls and $7 \%$ boys. 
There can be many causes for human trafficking and these causes vary from country to country. People who find themselves in vulnerable situations fall prey to traffickers.

\section{Human Trafficking in Sri Lanka}

Sri Lanka is primarily a source, destination, and to a lesser extent, a transit country for men, women and children subject to forced labour and sex trafficking as described by the Trafficking in Persons Report (TiP, 2018). Sri Lankan men and women migrate willingly to Middle Eastern countries such as Kuwait, Jordan, Saudi Arabia, Qatar, Lebanon, the United Arab Emirates, Oman and Bahrain, and to a Southeast Asian country like Singapore to work as construction workers, domestic servants or garment factory workers. Some of these workers find themselves in situations of involuntary servitude when faced with restrictions on movement, withholding of passports, threats, physical or sexual abuse, and debt bondage that is, in some instances, facilitated by large pre-departure fees imposed by labour recruitment agencies and their unlicensed sub-agents. Therefore, majority of suspected cases of trafficking reported in Sri Lanka are from the migrant workers. The root causes for trafficking can be the civil war, economic hardships, high rates of internal and foreign labour migration etc. Internal trafficking is very much a hidden crime in Sri Lanka whereby the authorities are seemingly aware that it exists and the government has taken notable measures in the reporting, prevention and detection of this heinous crime.

Unlike many other Asian countries, the extent of trafficking remained relatively unknown in Sri Lanka until early 2000, due to the subversive and hidden nature of this crime, law enforcement, particularly local Police found it difficult to identify victims, who may be hidden within the communities and reluctant to complain due to economic reasons and social and cultural stigma attached to the crime. Nonetheless as a result of the continuing efforts by the government of Sri Lanka, the law enforcement authorities have showed a significant effort in preventing protecting and prosecuting trafficking in person in the recent years.

\section{Legal Framework in Sri Lanka}

Sri Lanka ratified the United Nations Convention on Transnational Organized Crime (UNTOC) in September 2006. The supplementary protocol to the UNTOC, the Palermo Protocol the Protocol to Prevent, Suppress and Punish Trafficking in Persons, especially Women and Children was signed in December 2000 and ratified in June 2015.

In accordance with international laws the Penal Code was amended in 2006, prohibiting all forms of trafficking in Sri Lanka. A national policy on migration that promises to prevent the trafficking of Sri Lankan migrants is already in place.

This paper is a reflection of my experience as Senior Coordinator of IOMs Combating Human Trafficking project where we encountered the first human trafficking case in Sri Lanka. Three traffickers were indicted in Colombo High Court and convicted under Section 360C of the Penal Code for the crime of human trafficking.

\section{Part II}

\section{Complexity of human trafficking}

\section{Uzbek case facts in brief}

Uzbek case was the first human trafficking case reported in Sri Lanka where all three traffickers were convicted in 2011 . 
The victims of this case were two female Uzbek nationals brought to Sri Lanka on the promise of employment at restaurants. The first Defendant (Trafficker), who is also an Uzbek national (married to a Sri Lankan who was the second Defendant at the trial), used her contacts in Uzbekistan and arranged visa and other documents for the victims. Upon arrival in Sri Lanka, the first and second Defendants have met with the victims and taken to a house occupied by the first and second Defendants and used in the commercial sex industry. The second and third Defendants have accompanied the victims when they were engaged in acts of prostitution on prior arrangements made by the first Defendant with various persons. The money earned through such activity was taken by either second or third Defendant. The victims were taken to hotels and houses in that manner.

The defendants have also taken the victims to the Maldives on similar assignments. The third Defendant worked as a driver for the first Defendant and transported the victims to various places and collected the earnings. While they were in Sri Lanka, the first Defendant had engaged them at a brothel situated in Colombo where the police raided and the victims were under arrest. However, after they were bailed out, the first Defendant has taken them back and continued to use them in the same industry.

The victims escaped the custody of the Defendants and complained to the immigration authorities that their passports are held by the Defendants. Further inquiries by the immigration authorities and police have concluded that that there had been trafficking and prostitution of the victims.

The United Nations considers human trafficking as a crime against humanity that involves 3 elements; recruitment, by means coercion for the purpose of exploitation as aforementioned in the definition.

The practice of trafficking for commercial sex exploitation shows that each of its stages (recruitment, transportation, entry into a country, exploitation and criminal proceeds) is associated with related crimes, against either specific individuals or the State. For instance, recruitment involves fraudulent promises or kidnapping perpetrated against the individual victim. Transportation and entry may involve assault, rape, false imprisonment, forced prostitution (against victims) and violations of immigration laws (against the State). During the exploitation stage, trafficked persons are victims of coercion, threat and extortion, false imprisonment, forced prostitution, domestic violence, rape or sexual assaults, and in some cases manslaughter or murder. Making use of criminal proceeds from trafficking and exploitation involves money laundering and tax evasion and crimes against the State. Most stages may entail corruption of government officials and at times document forgery.

Trafficking involving sexual exploitation commonly refers to the exploitation of persons for prostitution, entertainment, and pornography, and is now increasingly understood - where it occurs for the purpose of exploitation - to encompass forced or arranged marriages, "mail order" brides, temporary wives or marriages of convenience. Trafficking does not require transportation or the crossing of international borders; women and children are victimized by trafficking in their own countries and abroad.

\section{Linking the three elements of the definition to the case}

\section{First element the Act of Recruitment}

Taking note of the definition as mentioned above, it is noticeable that there are three main components or elements namely: the act, the means and the purpose.

The element of Act or recruitment and harbouring of the victims of this case were fulfilled by the 1st defendant. The victims stated that the visa and other travel documents were prepared and arranged by the 1 st defendant. A relative who was also the agent of the 1st defendant in Uzbekistan advised the victim that the 1stdefendantwill receive her on arrival at the Colombo airport. Upon arrival the victims were received by the 1 stand 2nddefendantsand taken to their home. The victims claimed that they trusted the 1 st defendant as she is an 
Uzbek national and spoke their language. As the traffickers and victims shared the same national, ethnic and cultural background, it allowed the trafficker to better understand and exploit the vulnerabilities of the victims. From the time of recruitment until the time of arrival in Sri Lanka the traffickers were able to maintain trust to the victims. It is evident from the above factors that the victims had no reason to feel suspicious during the recruitment stage.

\section{Second element}

Victims of human trafficking are frequently lured by false promises of a lucrative job, stability, education, or a loving relationship.

The victims claimed that after arriving at the 1st and 2nddefendants' residence, the passports of the victims were taken by the traffickers. The victims were threatened and asked to get dressed by the defendants and were accompanied to hotels for prostitution. The 1st defendant made prior arrangements with clients over the phone and the victims were taken to hotels and houses by the 2 nd or 3 rddefendants. The victims claimed that they were used for prostitution instead of the promised jobs in restaurants. Fulfilling the second element; Means of deception and threat.

The challenge of proving trafficking for sexual exploitation is the difficulty of defining consent. Victims often consent to the initial stage of trafficking because they are misled or deceived by traffickers. The Protocol notes that initial consent does not mean an individual is consenting to the full trafficking process. Further, if any of the improper means set out in the definition (i.e. coercion, fraud, deception, threat) have been used, any alleged consent to the subsequent exploitation is irrelevant. Under section $360 \mathrm{C}$ (b) of the Amendment Act, any minor (under 18 years of age) he/she cannot consent to exploitation. As it's clear from the victims testimony in this case that the victims were promised jobs in restaurants but used for prostitution once they arrived in the country. Moreover, the victims were threatened to death if they refused to obey their orders. They were physically not able to leave the place as the traffickers provided accommodation for the victims in their residence and their passports were in the possession of the traffickers. On the other hand, the victims were foreigners without any identity and did not speak English or the local language.

The victims testified that they escaped from the traffickers and complained to the Department of Immigration and Emigration (IED) where the immigration informed the Criminal Investigations Department of the Police (CID). A team of police officers arrived at the 1stdefendant's house with the victims. When the victims identified the 1 stdefendant to the officers, she was questioned by the officers regarding their passports. The 3rd defendant (the driver) handed over the passports to the officers. The possession of passports belonging to another person is violating immigration law of Sri Lanka, thereby committing a crime against the State.

\section{Third element}

The $1^{\text {st }}, 2^{\text {nd }}$ and $3^{\text {rd }}$ defendants used the victims for the purpose of sexual exploitation by selling them for prostitution, fulfilling the third element: Purpose. The money earned through such activity was taken by either the second or third Defendant.

The victims testified that the 3rd defendant took each of the victims to the Maldives where they were used for prostitution; they also testified that they were sold to 8-10 clients a day and the money earned were taken by the 3rd defendant. The passports of the victims were produced in court as evidence for the visit to the Maldives. Victims further stated that as soon as they returned from the Maldives the 1st and 2nd defendants took their passports under their possession.

Human trafficking as defined above is not a single crime but a process. Factors lead to trafficking are wide ranging and complex and can include poverty, globalization, corruption, weak rule of law. Poverty lead the 
victims in this particular case, deceived believing that they have been hired for a real job, before finding themselves trapped and powerless. They trusted the traffickers as they are from the same village and speaking the same language.

The victims escaped with the help of a client who brought them to the department of immigration where they made their complaint regarding the confiscation of their passports by the traffickers. It is noteworthy to mention that after the victims complained to the immigration department the victims were referred to the CID, they were then transferred to a private shelter given there was no State Shelter available for victims during that time. The shelter was surrounded by traffickers and the Manager was threatened by the traffickers. Subsequent to the threats received by the shelter staff from traffickers the victims were immediately transferred to the immigration detention centre under police protection for safety. The victims were kept in the detention centre until the court proceedings were completed and repatriated to their country. The project staff of the Human Trafficking Unit of IOM provided all the assistance to the victims during the period the victims were kept in the detention centre.

\section{Part III}

The essence of human trafficking is the acquisition of control over people by improper means such as force, fraud or deception, with the aim of exploiting them.

\section{Control methods in the present case study}

Several researchers have looked into control methods used by human traffickers against sexual exploitation. Hughes (2011) describes four different control methods: the confiscation of travel documents, the use of violence, the threat to harm family members and a financial dependency upon the human traffickers. Logan (2009) demonstrated that the control methods could be distinguished in four different themes: firstly, fear which include fear of physical and sexual violence, fear of deportation, fear of legal problems, lack of trust in the legal system and a general fear. Secondly, the lack of knowledge about alternatives in where victims are unaware of the available service in the destination country, do not know their own rights, do not see themselves as victims or do not have any other alternative. Thirdly, the isolation of the victims which includes lack of social support, absence of transportation methods, a language barrier and non-awareness of culturally appropriate services. Finally, the use of physical or psychological confinement. The physical form assigns the holding in captivity of the victim and the psychological way is through the feeling of shame.

There has been little research to date on psychological coercion of trafficking victims. Hopper (2006) discussed in her study about how psychological manipulation is used in various conditions of control. She noted significant similarities between hostages, political prisoners of concentration camps, battered women and other victims of captivity, with victims of trafficking; Deprivation of basic psychological needs such as food, sleep, isolation creating a sense of disconnection were describe as systematic and repetitive infliction of psychological trauma.

Among other control methods, bondage is a common method used by traffickers to coerce the victims and gain control over them; Debt bondage is a common control method used mainly for trafficking for labour exploitation and for sexual exploitation at a lesser extent. According to the report issued in March 2019 by UN Migration agency, a new control method was revealed on Nigerian victims of trafficking where they were submitted to a voodoo rite which bound them by contract to their traffickers, this particular contract, among other things, prohibits victims from revealing the name of their traffickers and other details that may lead to the identification of the exploitation. Fear of breaking the voodoo oath is an element of subordination which deeply affects the victims of trafficking.

Focusing on the control methods in the present study, from the victims' testimony it was observed that the traffickers used a combination of all the methods discussed by aforementioned researchers. As described by 
Hughes (2011), the travel documents of the victims in this case were confiscated as soon as they first arrived in the country and as soon as they returned from the Maldives. They were threatened with physical harm if they failed to obey demands/orders of the traffickers. The traffickers provided accommodation and transportation for the victims making them financially dependent upon the traffickers.

The victims were threatened with physical harm by the traffickers as a technique to promote victim's submission. They were threatened with death if they refused to fulfil their demands for prostitution. In comparison to the control methods under four themes demonstrated by Logan, the victim revealed similarities such as fear of physical and sexual violence from the traffickers and fear of legal problems.

It was revealed from the victims' testimony that they were used for prostitution at a brothel in Colombo which was raided by the police. Subsequently, they were released on bail by the 2 nd defendant on the request of the son of the owner of the said brothel. It is apparent that the victims feared legal problems and had a lack of trust on the legal system as a result of this incident. It is evident from the victims' statements that they experienced high level of fear in the situation. This frequent fear they experienced played a central role which kept them entrapped in the situation.

Victims testified that they were unaware of alternatives to seek protection from available services. The reasons being that they were total strangers in a foreign land unable to understand or speak English or the local language. As a result they were unable to learn or understand the rights or sources of information or services/institutions to seek help. These are similar to second and third methods discussed by Logan (2009). The victims were uneducated to understand that their rights being violated by the traffickers and they are victims of a crime. As described by Logan (2009) under the fourth method, the victims were isolated given that they were provided accommodation at the trafficker's residence, and language barrier as they did not speak English. By providing accommodation the traffickers increased the dependence of the victim on the trafficker. Similar to financial dependency as described by Hughes (2011); The only persons whom they could communicate in their language were the $1^{\text {st }}$ and $2^{\text {nd }}$ defendants. On one hand the victims were more comfortable in communicating with the traffickers as they were the only persons who spoke their native language, as they were separated from their families, and living in a foreign land the victims became more and more dependent on the traffickers. On the other hand for the traffickers it's a powerful tool to reduce resistance attempts from the victims.

Victims were physically and psychologically confined. Physically the victims were in captive; they were confined to the trafficker's residence and escorted to brothels by the 3rd defendant who was the driver of the vehicle owned by the traffickers. Psychological control was evident via psychological shame and humiliation by threatening to tell family and villagers exposing the job they were doing. As stated by the victims, they were recruited by a relation of the 1 st defendant who was from the same village. The traffickers used threats to shame the victims by way of exposing their circumstances to their families and villagers through the person whom they were recruited in their village in Uzbekistan. It is observed that in this particular case the traffickers (1st defendant) and the victims shared the same national, ethnic and cultural background which allowed the traffickers to better understand and exploit the vulnerabilities of the victims.

Although the traffickers allowed the victims to speak to their mothers, it was only using the phone of the 1 st defendant in her presence for a very limited time. Since the victims were under close watch of the traffickers, they were unable to inform their families of the situation they were in. Moreover, the victims' further testified that the traffickers provided food and clothing to the victims and were also accompanied to hospital when they fell sick. This way the traffickers were able to build trust and the victims were psychologically and financially dependent on them. This can be observed as a powerful control strategy used by the traffickers.

It is apparent from the case study that the traffickers applied several means of control on the victims throughout the trafficking process. The control methods used on victims of trafficking discussed by several researchers in this study show similarities. 
It is observed from the testimony of the victims of this particular case study that the traffickers used psychological manipulation and fear more than physical violence to maintain control over the victims. The definition of trafficking under Article 3 of the Protocol, coercion includes violent as well as non-violent or psychological force. The definition describes how traffickers abuse their power or take advantage of others' vulnerabilities in order to coerce or control them. It further acknowledges that traffickers utilize psychological manipulation and fear to maintain control, making "representations to their victims that physical harm may occur to them or others should the victim escape or attempts to escape." It is not necessary to use violence often to keep the victim in a constant state of fear. The threat of death or serious harm (either to the victim or to others close to the victims) is much more frequent than the actual resort to violence.

As described by Hopper (2006), the victims of this case study were isolated from external social support networks, creating a sense of disconnection and experienced repeated verbal abuse, threats, and sexual abuse.

Hence, it is clear that psychological coercion is a dominant feature of this case study.

\section{Limitations}

To the author's knowledge, this is the first attempt of analysing control methods of a case of human trafficking for sexual exploitation, given that this is the very first case that the traffickers were convicted in Sri Lanka. The study was limited to only one case and two victims seeing that it was the first and the only human trafficking case where the traffickers were convicted so far. Moreover, this study did not take into consideration men and children.

\section{Conclusion}

The present case study is only the first step to understand the complexity of human trafficking and to identify different control methods used against victims. The control methods used against the victims of this case compared to the control methods discussed by other researchers are almost similar. Nonetheless, this study contributes to the fight of human trafficking in an indirect manner enhancing the understanding of the complexity of the crime and control methods. Additionally, this is an eye opener for anti-trafficking advocates to seek out individual victims to describe the reality of trafficking. It is apparent from this case that victim based initiatives are necessary both to assist victims and provide a firmer basis for future trafficking prosecutions.

Future studies of this nature would benefit the identification of variations of control methods in order to address better prevention methods.

After this case the government of Sri Lanka took several notable measures to protect victims of trafficking; for example: shelter facilities and Standard Operating Procedures (SOP), among other steps.

\section{References}

United Nations Office of the High Commissioner for Human Rights (2000)Protocol to Prevent, Suppress and Punish Trafficking in Persons Especially Women and Children, supplementing the United Nations Convention against Transnational Organized Crime. [Online]. Available from:https://www.ohchr.org/en/professionalinterest/pages/protocoltraffickinginpersons.aspx[Accessed 02.02.2019]

United Nations Office on Drugs and Crime (2018) Global Report on Trafficking in Persons. Worldwide: United Nations [Online]. Available from: https://www.unodc.org/documents/data-andanalysis/glotip/2018/GLOTiP 2018 BOOK web small.pdf[Accessed 02.02.2019]

Department of State (2018) Trafficking in Persons Report. United States of America: Department of State [Online]. Available from: https://www.state.gov/documents/organization/282798.pdf[Accessed 02.07.2019] 
Parliament of the Democratic Socialist Republic of Sri Lanka (2006) Penal Code(Amendment) Act, No. 16 of 2006. Sri Lanka: Gazette of the Democratic Socialist Republic of Sri Lanka [Online]. Available from: file:///D:/User\%20Profile/Downloads/LKA74477\%20(1).pdf[02.07.2019]

Hughes, D. (2011) The Natasha Trade: Transnational sex trafficking. National Institute of Justice Journal [Online]. Available from: https://www.ncjrs.gov/pdffiles1/jr000246c.pdf[Accessed 02.11.2019]

Hopper, E., Hidalgo, J. (2006) Invisible chains: psychological coercion of human trafficking victims. Intercultural Human Rights Law Review [Online]. Available from: https://www.stu.edu/Portals/law/docs/human-rights/ihrlr/volumes/1/185-209-Elizal, [Accessed 02.05.2019]

Logan T.,Walker,R and Hunt, G. (2009) Understanding Human Trafficking in The United States. Trauma, $\begin{array}{llllll}\text { Violence, } & \& & \text { Abuse, } & \text { [Online]. } & \text { Available }\end{array}$ https://journals.sagepub.com/doi/pdf/10.1177/1524838008327262[Accessed 03.04.2019] 